\title{
Treatment as prevention: will it work?
}

M J van de Laar (marita.van.de.laar@ecdc.europa.eu)1, A Pharris ${ }^{1}$

1. European Centre for Disease Prevention and Control (ECDC), Stockholm, Sweden

Citation style for this article:

van de Laar MJ, Pharris A. Treatment as prevention: will it work?

Euro Surveill. 2011;16(48):pii=20029. Available online: http://www.eurosurveillance.org/ViewArticle.aspx?Articleld=20029

In the past two years, rapidly emerging new trial results have provided the scientific community and people living with human immunodeficiency virus (HIV) or acquired immune deficiency syndrome (AIDS) or at risk of infection, with welcome news. Interesting scientific evidence is accumulating for the effectiveness of biomedical interventions to prevent the transmission of HIV. Infected people may become less contagious when the viral load is suppressed by antiretroviral therapy (ART). In 2010, results from the Pre-Exposure Prophylaxis Initiative (iPreX) randomised controlled trial provided the first evidence that antiretroviral preexposure prophylaxis can reduce HIV incidence. In their study, Grant et al showed, that that daily oral antiretroviral medication reduced HIV incidence in HIV negative men who have sex with men (MSM) by $44 \%$ [1]. In July 2011, two studies from the United States, the TDF2 (tenofovir disoproxil fumarate and emtricitabine (TDF)) study and the Partners Pre-exposure study provided evidence that a daily oral dose of antiretroviral medication can reduce HIV acquisition among uninfected individuals exposed to the virus through heterosexual sex by at least $60 \%$ [2-3]. The randomised controlled HIV Prevention Trials Network study (HPTN 052) by Cohen et al demonstrated that earlier treatment (time of enrolment in study compared with $C D_{4}$ cell counts within or below 200-250 cells $/ \mathrm{mm}^{3}$ or developing an AIDS defining illness) of HIV-infected persons with ART had both a clinical benefit for the infected individual and resulted in a $96 \%$ reduction in transmission to the uninfected sexual partner [4].

Early treatment for HIV, prevention of mother-to-child transmission, post-exposure prophylaxis, male circumcision, consistent condom use, behaviour change communication, microbicides, and possibly targeted pre-exposure prophylaxis are the most effective tools to prevent HIV transmission on individual and population levels [2-6]. Mathematical modelling studies indicated that early testing and early treatment of all individuals with HIV could effectively halt HIV transmission at the population level. Ecological studies have confirmed the effectiveness of the test and treat strategy in reducing HIV transmission and it appears to be bolstered further by HPTN 052 trial results [7-11].
New data on HIV in Europe in this issue by Likatavicius and Van de Laar demonstrate that HIV remains a public health problem in the European Union (EU) and European Economic Area (EEA) where more than 27,000 newly diagnosed HIV infections were reported during 2010 [12] (an increase of $4 \%$ compared with 2009). HIV diagnoses among men who have sex with men (MSM) have increased by 39\% between 2004 and 2010, and represent $38 \%$ of the total HIV cases in the EU/EEA. New HIV diagnoses among injecting drug users (IDU) have declined by $44 \%$ since 2004 , representing only $4 \%$ of cases in 2010 . However, outbreaks of HIV in this group have been reported in some countries recently [13-14] and the prevalence of HIV and hepatitis C remains high as reported in this issue by Wiessing et al. [15]. The proportion of people diagnosed with a $C D_{4}$ cell count less than $350 / \mathrm{mL}$ (late diagnosis) [1, 16-17] is unacceptably high in Europe: almost half of the cases where a $C D$ cell count was available at the time of diagnosis. This suggests that individuals present late in the course of infection, cannot benefit from early treatment and are at risk of disease progression.

The potential and feasibility of treatment as prevention needs to be considered in light of the current epidemiological situation of HIV in Europe. For antiretroviral treatment to have a preventive effect, the HIV-positive individual's viral load must be suppressed to a very low level over time. Gardner et al. modelled the achievement of viral suppression by using the pre-requisite steps testing and diagnosis, linking to care, adherence to ART, and viral load suppression as the final outcome. They demonstrate that in order to achieve a sustained population-level reduction in viral load a high proportion of HIV-infected individuals must be i) diagnosed with HIV infection, ii) linked in a timely manner to HIV care, iii) retained in care, iv) placed on effective antiretroviral therapy and v) adherent life-long to this treatment [18]. The steps in this care cascade were reviewed and many individuals seem to drop out of at one of the steps. If all efforts would be maximised to $90 \%$ for all steps still only an estimated two-third of the cases would achieve viral suppression. 
The care cascade points out key areas for programme and surveillance improvement within Europe. In addition to late testing and diagnosis of HIV, most Member States do not routinely monitor whether people tested positive for HIV are linked to care and, if so, whether they are retained in care. Monitoring access to and retention in care is particularly important for vulnerable populations among those living with HIV, including MSM, IDUs and migrants. Monitoring and surveillance systems should be adapted so that they track engagement in care more effectively and allow monitoring the impact of treatment on the course of the epidemic.

HIV testing, early diagnosis and access to early treatment have always been key strategies for HIV/AIDS prevention. New evidence for biomedical interventions is indeed promising and shows that knowledge of HIV status has now become the cornerstone for HIV prevention. However, the question arises as to whether the implementation of prevention treatment strategies is feasible and affordable as the trial results were obtained under optimised conditions. A recent costeffectiveness study has highlighted that in addition to HIV testing and treatment substantial reductions in risk behaviour are still needed to contribute to substantial reductions in HIV transmission [19]. Treatment as prevention as an option in Europe is complicated by the fact that the HIV epidemic affects mostly socially vulnerable or marginalised groups who experience multiple barriers to accessing services and adhering to treatment. At the same time, a combination prevention toolkit is available with multiple effective programmatic, behavioural and structural interventions at different levels that can be tailored to local epidemics.

Interventions found to be consistently effective include condom provision, reduction of number of sex partners, partner notification services, needle and syringe exchange programmes, opioid substitution treatment, and behavioural change interventions [20-24]. At present there is little evidence that treatment as prevention works among MSM [25] and in light of the current epidemiological situation more efforts are needed to reverse the trend of sexually transmitted infections and HIV among MSM through combined measures. The evidence for harm reduction and prevention of communicable diseases in the field of drug use is overwhelming. A recently launched ECDC/EMCDDA guidance document brings together evidence and expert opinion and supports EU countries to reduce the burden of drug use as well as the burden of high prevalence of HIV, hepatitis B and C among IDUs [26]. It was launched at a critical moment when an outbreak of HIV among IDUs was reported [13]. In this issue, Pharris et al investigate recent outbreaks in Greece and Romania and assess the risk for HIV transmission among IDUs in Europe [27]. The analysis show a heterogeneous pattern in with a potential risk for outbreaks in a number of countries where immediate action is warranted. It demonstrates the need for having adequate prevention services in place to prevent outbreaks of
HIV and hepatitis C. Outbreaks can be expected when drug using patterns change, the frequency of injection increases in combination with a low coverage of prevention services (including needle exchange programmes and opioids substitution treatment).

In the context of the Joint United Nations Programme on HIV/AIDS (UNAIDS) 2011 political declaration 'targets and elimination commitments' [28] to achieve zero new infections, no AIDS-related deaths and zero discrimination by 2015 , we need to review the current HIV prevention strategies in Europe and to re-enforce the respective programmatic approach. With enough people in treatment, the treatment as prevention option will help to reduce HIV transmission however, there is as of yet no evidence that this will reverse HIV trends in Europe. To control the epidemic, primary and secondary prevention of HIV transmission remains crucial. To identify and apply the most effective prevention strategies to reduce the impact of HIV in Europe, there is an urgent need for better programmatic approach, involving a wide range of stakeholders including healthcare providers, civil society, those infected with HIV and prevention workers.

\section{References}

1. Grant RM, Lama JR, Anderson PL, McMahan V, Liu AY, Vargas L, et al. Preexposure chemoprophylaxis for HIV prevention in men who have sex with men. N Engl J Med. 2010;363(27):2587-99.

2. Thigpen MC, Kebaabetswe PM, Smith DK, Segolodi TM, Soud FA, Chillag K, et al., for the TDF2 Study Group. Daily oral antiretroviral use for the prevention of HIV infection in heterosexually active young adults in Botswana: results from the TDF2 study. 6th International AIDS Society Conference on HIV Pathogenesis, Treatment and Prevention; 2011 July 17-20; Rome, Italy.

3. University of Washington International Clinical Research Center. Pivotal study finds that HIV medications are highly effective as prophylaxis against HIV infection in men and women in Africa. Partners PrEP Study. [Press Release]. Available from: http://depts.washington.edu/astda/resources/ PrEP PressRelease-UW_13Jul2011.pdf Full study : Mujugira A, Baeten JM, Donnell D, Ndase P, Mugo NR, Barnes L, et al. Characteristics of HIV-1 serodiscordant couples enrolled in a clinical trial of antiretroviral pre-exposure prophylaxis for HIV-1 prevention. PLoS One. 2011; 6(10):e25828.

4. Cohen MS, Chen YQ, McCauley M, Gamble T, Hosseinipour MC, Kumarasamy N, et al. Prevention of HIV-1 infection with early antiretroviral therapy. N Engl J Med. 2011;365(6):493-505.

5. Abdool Karim Q, Abdool Karim SS, Frohlich JA, Grobler AC, Baxter C, Mansoor LE, et al. Effectiveness and safety of tenofovir gel, an antiretroviral microbicide, for the prevention of HIV infection in women. Science. 2010;329(5996):1168-74.

6. Padian NS, McCoy SI, Karim SS, Hasen N, Kim J, Bartos M, et al. HIV prevention transformed: the new prevention research agenda. Lancet. 2011;378(9787):269-78.

7. Granich RM, Gilks CF, Dye C, De Cock KM, Williams BG. Universal voluntary HIV testing with immediate antiretroviral therapy as a strategy for elimination of HIV transmission: a mathematical model. Lancet. 2009;373(9657):48-57.

8. Das M, Chu PL, Santos GM, Scheer S, Vittinghoff E, McFarland $W$, et al. Decreases in community viral load are accompanied by reductions in new HIV infections in San Francisco. PLoS One. 2010;5(6):e11068.

9. Donnell D, Baeten JM, Kiarie J, Thomas KK, Stevens W, Cohen CR, et al. Heterosexual HIV-1 transmission after initiation of antiretroviral therapy: a prospective cohort analysis. Lancet. 2010;375(9731):2092-8.

10. Wood E, Kerr T, Marshall BD, Li K, Zhang R, Hogg RS, et al. Longitudinal community plasma HIV-1 RNA concentrations and incidence of HIV-1 among injecting drug users: prospective cohort study. BMJ. 2009;338:b1649. 
11. Attia S, Egger M, Muller M, Zwahlen M, Low N. Sexual transmission of HIV according to viral load and antiretroviral therapy: systematic review and meta-analysis. AIDS 2009;23(11):1397-404.

12. European Centre for Disease Prevention and Control, WHO Regional Office for Europe. HIV/AIDS Surveillance in Europe: 2010. Stockholm, 2011. Available from: http://ecdc.europa.eu/ en/publications/Publications/101129_SUR_HIV_2009.pdf

13. Paraskevis D, Nikolopoulos G, Tsiara C, Paraskeva D, Antoniadou A, Lazanas M, et al. HIV-1 outbreak among injecting drug users in Greece, 2011: a preliminary report. Euro Surveill. 2011;16(36). Available from: http://www. eurosurveillance.org/ViewArticle.aspx?Articleld =19962

14. European Monitoring Centre for Drugs and Drug Addiction. Annual Report 2011: The state of the drugs problem in Europe. Lisbon: EMCDDA 2011. Available from: http://www.emcdda.europa.eu/attachements.cfm/ att_143743_EN_EMCDDA_AR2011_EN.pdf

15. Wiessing L, Likatavicius G, Hedrich D, Guarita B, Van de Laar $M$, Vicente J. Trends in HIV and hepatitis $C$ virus infections among injecting drug users in Europe, 2005 to 2010. Euro Surveill. 2011;16(48):pii=20031. Available from: http://www. eurosurveillance.org/ViewArticle.aspx?Articleld=20031

16. Likatavicius G, van de Laar MJ. HIV infection and AIDS in the European Union and European Economic Area, 2010. Euro Surveill. 2011;16(48):pii=20030. Available from: http://www. eurosurveillance.org/ViewArticle.aspx?Articleld $=20030$

17. European Centre for Disease Prevention and Control. Technical Report: Increasing the uptake and effectiveness in the European Union: Evidence synthesis for Guidance on HIV testing. Stockholm: ECDC; 2010. Available from: http://ecdc. europa.eu/en/publications/Publications/101129_TER HIV testing_evidence.pdf

18. Gardner EM, McLees MP, Steiner JF, Del Rio C, Burman WJ. The spectrum of engagement in HIV care and its relevance to testand-treat strategies for prevention of HIV infection. Clin Infect Dis. 2011;52(6):793-800.

19. Long EF, Brandeau ML, Owens DK. The cost-effectiveness and population outcomes of expanded HIV screening and antiretroviral treatment in the United States. Ann Intern Med. 2010;153(12):778-89.

20. Coates TJ, Richter L, Caceres C. Behavioural strategies to reduce HIV transmission: how to make them work better. Lancet. 2008;372(9639):669-84.

21. Piot P, Bartos M, Larson H, Zewdie D, Mane P. Coming to terms with complexity: a call to action for HIV prevention. Lancet. 2008;372(9641):845-59.

22. European Centre for Disease Prevention and Control, European Monitoring Centre for Drugs and Drug Addiction. Evidence for the effectiveness of interventions to prevent infections among people who inject drugs. Part 1: Needle and syringe programmes and other interventions for preventing hepatitis C, HIV and injecting risk behaviour. Stockholm: ECDC; 2011. Available from: http://www.emcdda.europa.eu/attachements. cfm/att_145115_EN_ECDC-EMCDDA\%20Part\%201\%20web.pdf

23. European Centre for Disease Prevention and Control, European Monitoring Centre for Drugs and Drug Addiction. Evidence for the effectiveness of interventions to prevent infections among people who inject drug, Part 2: Drug treatment for preventing hepatitis C, HIV and injecting risk behaviour among people who inject drugs. Stockholm: ECDC; 2011. Available from: http://ecdc.europa.eu/en/publications/Publications/111129_ TER_ECDC-EMCDDA_part2.pdf

24. European Centre for Disease Prevention and Control. Technical Report. Effectiveness of behavioural and psychosocial HIV/STI prevention interventions for MSM in Europe. Stockholm: ECDC, 2009. Available from: http://ecdc.europa.eu/en/publications/ Publications/0911_TER_Lit_Review_Effect_HIVSTI_prev_ interv_for_MSM.pdf

25. Kelley CF, Haaland RE, Patel P, Evans-Strickfaden T, Farshy C, Hanson D, et al. HIV-1 RNA rectal shedding is reduced in men with low plasma HIV-1 RNA viral loads and is not enhanced by sexually transmitted bacterial infections of the rectum. J Infect Dis. 2011;204(5):761-7.

26. European Centre for Disease Prevention and Control, European Monitoring Centre for Drugs and Drug Addiction. Prevention and control of infectious disease among people who inject drugs. Stockholm: ECDC, 2011. Available from: http://www. ecdc.europa.eu/en/publications/Publications/111012 Guidance_ECDC-EMCDDA.pdf

27. Pharris A, Wiessing L, Sfetcu O, Hedrich D, Botescu A, Fotiou $A$, et al. Human immunodeficiency virus in injecting drug users in Europe following a reported increase of cases in Greece and Romania, 2011. Euro Surveill. 2011;16(48):pii=20032. Available from: http://www.eurosurveillance.org/ViewArticle. aspx?Articleld $=20032$
28. Joint United Nations Programme on HIV/AIDS (UNAIDS). 20112015 strategy: Getting to zero. UNAIDS, Geneva: UNAIDS, 2010. Available from: http://www.unaids.org/en/media/ unaids/contentassets/documents/unaidspublication/2010/ JC2034_UNAIDS_Strategy_en.pdf 